\title{
Exploring regulation and function of dopamine D3 receptors in alcohol use disorder. A PET $\left[{ }^{11} \mathrm{C}\right]-(+)-$ PHNO study
}

\author{
Chidera C. Chukwueke ${ }^{1,2 \bowtie}$, Christina N. Nona ${ }^{3}$, Matthew D. McPhee ${ }^{4}$, Esmaeil Mansouri D $^{5}$, Dafna S. Rubin-Kahana ${ }^{1,6}$, \\ Diana Martinez ${ }^{7,8}$, Isabelle Boileau (iD ${ }^{5,6}$, Christian S. Hendershot ${ }^{9,10}$ and Bernard Le Foll (iD) ${ }^{1,2,4,6,11,12}$
}

(c) The Author(s), under exclusive licence to American College of Neuropsychopharmacology 2021

Preclinical studies support an important role of dopamine D3 receptors (DRD3s) in alcohol use disorder (AUD). In animals, voluntary alcohol consumption increases DRD3 expression, and pharmacological blockade of DRD3s attenuates alcohol self-administration and reinstatement of alcohol seeking. However, these findings have yet to be translated in humans. This study used positron emission tomography (PET) and $\left[{ }^{11} \mathrm{C}\right]-(+)-$ PHNO to compare receptor levels in several dopamine D2 receptor (DRD2) and DRD3 regions of interest between AUD subjects in early abstinence $(n=17 ; 6.59 \pm 4.14$ days of abstinence) and healthy controls $(n=18)$. We recruited non-treatment seeking subjects meeting DSM-5 criteria for AUD. We examined the relationship between DRD2/3 levels and both alcohol craving and alcohol motivation/wanting, using a cue reactivity procedure and an intravenous alcohol selfadministration (IVASA) paradigm, respectively. $\left[{ }^{11} \mathrm{C}\right]-(+)-\mathrm{PHNO}$ binding levels in AUD subjects were significantly lower than binding in HCs when looking at all DRD2/3 ROls jointly (Wilk's $\Lambda=.58, F(6,28)=3.33, p=0.013, \eta_{p}^{2}=0.42$ ), however there were no regionspecific differences. Binding values demonstrate $-12.3 \%$ and $-16.1 \%$ lower $\left[{ }^{11} \mathrm{C}\right]-(+)-$ PHNO binding in the SMST and SN respectively, though these differences did not withstand Bonferroni corrections. There was a positive association between $\left[{ }^{11} \mathrm{C}\right]-$ $(+)$-PHNO binding in the SN (almost exclusively reflective of DRD3) and alpha (lower values reflect higher alcohol demand) in the APT after Bonferroni corrections $(r=0.66, p=0.0080)$. This demonstrates that AUD subjects with lower DRD3 levels in the SN exhibit increased demand for alcohol. These results replicate previous findings demonstrating reduced DRD2/3 levels while also supporting a lack of DRD3 upregulation and potential downregulation in early abstinent AUD. Furthermore, the finding that binding in the $\mathrm{SN}$ is associated with alcohol demand warrants further examination.

Neuropsychopharmacology (2021) 46:2112-2120; https://doi.org/10.1038/s41386-021-01095-2

\section{INTRODUCTION}

Almost 100 million disability-adjusted life-years were attributable to alcohol use around the world in 2016 [1]. In 2015, there were an estimated 63.5 million cases of alcohol use disorder (AUD) globally [2]. While psychosocial [3] and pharmaceutical [4] treatment options exist for this disorder, outcomes are moderate at best $[5,6]$, signifying the need for improved treatment options. The dopamine system has been implicated in AUD with the dopamine D2 receptors (DRD2) as the historical target of research [7]. Previous animal studies show that chronic consumption of alcohol reduces the expression of DRD2s $[8,9]$. In addition, some human neuroimaging studies, but not all $[10,11]$, have shown reduced DRD2 density in AUD subjects compared to healthy controls [12-14] which has been associated with craving and relapse $[11,15]$. Though there is some controversy [16], this line of research provides evidence in support of DRD2 involvement in AUD related processes.
In the last 20 years, the dopamine D3 receptor (DRD3) has gained research attention because of its highly localized expression along the mesolimbic dopamine pathway $[17,18]$ and its distinct drug-related function [19, 20]. In contrast to DRD2, some, but not all [21], preclinical studies have observed an upregulation in DRD3s in response to repeated exposure to cocaine [19] and nicotine [20]. These findings were corroborated in humans with studies showing increased DRD3 levels in the post-mortem brains of cocaine overdose subjects [22-24] as well as in in vivo investigations of methamphetamine [25] and polystimulant users [26]. Together, these findings suggest a potentially important role of DRD3s in drug-related processes with both preclinical and clinical investigations supporting upregulation of DRD3s in response to chronic drug exposure under some conditions.

Similarly, preclinical studies have observed increased DRD3 expression in rodents following alcohol consumption [27, 28]. Furthermore, blockade of DRD3s using selective pharmacological

\footnotetext{
${ }^{1}$ Translational Addiction Research Laboratory, Campbell Family Mental Health Research Institute, Centre for Addiction and Mental Health (CAMH), Toronto, ON, Canada.

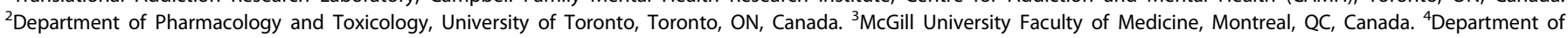

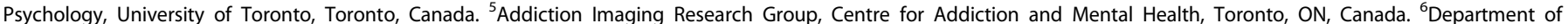

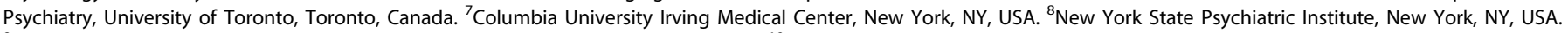

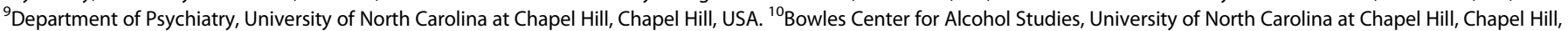

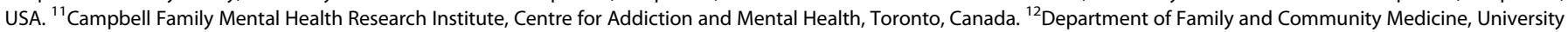
of Toronto, Toronto, Canada. ${ }^{\bowtie}$ email: chidera.chukwueke@mail.utoronto.ca
}

Received: 1 February 2021 Revised: 24 June 2021 Accepted: 7 July 2021

Published online: 4 August 2021 
antagonist (e.g., SB-277011-A) suggest an important role of DRD3 in influencing AUD phenotypes in animal models. For example, studies have shown that treatment with SB-277011-A reduced oral alcohol self-administration in rodents [29-31]. Additionally, compared to first-line approved AUD medications naltrexone and acamprosate [4], SB-277011-A reduced reinstatement of alcohol seeking (i.e., animal model of craving or relapse-like behaviour) in mice [30]. This finding was validated by another study showing a dose-dependent reduction of alcohol seeking reinstatement by SB-277011-A treatment in rats [27]. This line of research suggests an increase in DRD3 levels under conditions of repeated alcohol use, and a positive correlation between DRD3 levels or functioning and AUD phenotypes such as alcohol reinforcement and craving. In humans, the use of GSK598,809, a DRD3 antagonist, has shown to transiently alleviate nicotine craving in smokers [32], normalize the ventral striatal reward response in some AUD subjects [33], and reduce both appetitive responses and attentional bias to food cues in overweight individuals [34, 35]. Despite some promising clinical results regarding the utility of DRD3 antagonism as pharmacotherapy in addictions, the preclinical findings have not been conclusively translated in human subjects with substance use disorders, therefore more research is needed.

Positron emission tomography (PET) studies allow for the in vivo investigation of neurotransmitter activity and receptor density [36]. However, exploration of DRD3s in humans have been limited due to the scarcity of DRD3 selective radioligands. With the advent of $\left[{ }^{11} \mathrm{C}\right]-(+)-P H N O$, a DRD3 preferring agonist with 25 - to 48 -fold selectivity for DRD3 over DRD2 [37], it is now possible to explore DRD3 densities in vivo. Studies exploring the fraction of $\left[{ }^{11} \mathrm{C}\right]-$ $(+)$-PHNO signal that reflect DRD3 levels observe the following percentages in healthy male participants: hypothalamus, 90-100\%; substantia nigra (SN) 87-100\%; ventral pallidum (VP), 71-75\%; globus pallidus (GP), 65-66\%; limbic striatum (LST) 26$39 \%$, caudate (CD) 2-21\%, putamen (PT) 0-14\% [38, 39].

One PET study has employed the use of $\left[{ }^{11} \mathrm{C}\right]-(+)-\mathrm{PHNO}$ and a selective DRD3 antagonist, GSK598809, to examine DRD3 levels in AUD subjects compared to healthy controls [40]. This study found no difference in baseline $\left[{ }^{11} \mathrm{C}\right]-(+)-\mathrm{PHNO}$ binding, which reflects receptor levels, between AUD subjects and healthy control in all brain regions apart from the hypothalamus $\left(90-100 \%\right.$ of $\left[{ }^{11} \mathrm{C}\right]-$ $(+)$-PHNO binding signal in the hypothalamus is attributable to DRD3s $[38,39])$. These findings suggested a lack of global DRD3 upregulation in AUD subjects, contrary to predictions [40]. However, their AUD population had wide variation in abstinence periods with a mean ( \pm standard deviation [SD]) of $415 \pm 254$ (range: 39-893) abstinent days [40]. Therefore, it is currently unknown whether the lack of global DRD3 upregulation (except for in the hypothalamus) observed in the study is due to a recovery of DRD3 levels or a true lack of chronic alcohol induced DRD3 upregulation. Furthermore, no study has investigated the relationship between DRD3 receptor binding and human laboratory measures of AUD phenotypes such as alcohol craving and self-administration.

The current study examined the regulation of DRD3s using PET $\left[{ }^{11} \mathrm{C}\right]-(+)-\mathrm{PHNO}$ in early abstinent AUD subjects compared to healthy controls. Based on the preclinical research discussed above, we hypothesized increased $\left[{ }^{11} \mathrm{C}\right]-(+)$-PHNO binding in AUD subjects compared to healthy controls, specifically in DRD3-rich areas (i.e. SN, VP, GP). In addition, based on previous human neuroimaging studies, we expect to see decreased $\left[{ }^{11} \mathrm{C}\right]-(+)-\mathrm{PHNO}$ binding in DRD2-rich areas of interest (associate striatum [AST], sensorimotor striatum [SMST]) as well as in DRD2/3 mixed areas (LST). This study also explores the relationship between DRD3 levels in AUD subjects and motivation to consume alcohol, measured by an intravenous self-administration paradigm, as well as alcohol craving, measured by a cue-reactivity procedure. In line with previous research [27, 29-31], we hypothesize that higher
DRD3 levels among AUD subjects will be associated with increased alcohol motivation and craving. Finally, in an exploratory manner, we examine the relationship between $\left[{ }^{11} \mathrm{C}\right]-$ $(+)$-PHNO binding and various self-report measures of AUD phenotypes, including alcohol demand (i.e., the relative reinforcing value of alcohol).

\section{METHOD}

\section{Participants}

AUD participants. AUD subjects were non-treatment seekers recruited from the community in Toronto, Ontario, and invited for in-person assessments at the Centre for Addiction and Mental Health (CAMH) following a phone pre-screen. At the in-person eligibility assessment, consent was obtained before continuing with study procedures. All AUD participants were assessed for DSM-5 AUD criteria using a modified version of the Structured Clinical Interview for the DSM-IV (SCID) [41]. Demographic (e.g., age, gender, race, ethnicity) and drug use information were collected. AUD participants provided biological samples, including urine and blood for analysis of drug use and general health, as well as breath samples for breath alcohol concentration (BrAC) and carbon monoxide (CO) measurements for verification of smoking status (threshold for smoking status was $10 \mathrm{ppm}$ ). Eligible participants met DSM-5 criteria for AUD, had a negative urine drug screen (which tested for current use of all major illicit drugs and marijuana), and could abstain from drugs and alcohol prior to study visits. Exclusion criteria included other substance use disorders (SUDs) or other disorders, (e.g., mood and anxiety disorders, psychosis, etc.), history of seizures or suicide ideation, pregnancy, treatment seeking for AUD, and conditions or treatments that were contraindications for study procedures (e.g., medication for which alcohol is contraindicated and psychotropic medication). AUD participants that were deemed eligible were enroled in the study and invited to complete the following study procedures. All procedures were approved by the CAMH Research Ethics Board and were conducted according to the principles outlined in the Declaration of Helsinki. Eligible AUD participants were scheduled for the various study sessions (e.g., PET scan, cue reactivity, and IVASA). Sessions did not occur in a particular order and most sessions occurred on separate days. In some cases, the PET scan and cue-reactivity session occurred on the same day. For these cases, the PET scan occurred first in order to avoid cue effects on radioligand binding.

Control participants. Healthy controls (HCs) were selected out of previously recruited pool of healthy subjects that were scanned with $\left[{ }^{11} \mathrm{C}\right]-(+)-P H N O$ (recruitment criteria for these participants have been described elsewhere $[42,43])$. HCs were chosen to be matched on age, sex, ethnic background, and smoking status with the AUD population.

\section{PET imaging}

Abstinence. Participants underwent a single PET scan during early abstinence, where they were instructed to abstain from drinking for 2-7 days and abstain from smoking tobacco overnight prior to scanning. Participants attended an in-person visit during the abstinence period to verify alcohol abstinence by self-report and BrAC readings $(0.0 \mathrm{mg} \%)$; these measures were collected again immediately prior to scanning. Overnight abstinence from tobacco smoking was verified prior to scan using $\mathrm{CO}$ measurements (i.e., below 10 ppm). All withdrawal symptoms were monitored and managed by medical staff according to the guidelines in the supplementary material. One participant needed the engagement of the medical management of withdrawal protocol (Supplementary Material; Medical Management Protocol).

Image acquisition. The PET scan was performed using a high-resolution head-dedicated PET camera system (CTI PET Systems-High Resolution Research Tomography (HRRT), Siemens Medical Imaging, Knoxville, TN). This process has been described elsewhere [44]. The synthesis of $\left[{ }^{11} \mathrm{C}\right]-$ (+)-PHNO has also been describe elsewhere [45]. Participants underwent a standard proton density weighted brain magnetic resonance imaging (MRI) on a Discovery MR750 3 T MRI scanner (General Electric, 3 T MR750) to aid region of interest delineation of PET images.

Regions of interest (ROI). The ROls consisted of functional striatal areas (LST, AST, and SMST) and DRD3-rich extra striatal areas (SN, VP, GP). The delineation process has been previously described [42]. Outcome 
measures were $\mathrm{ROI}$ non-displaceable binding potentials $\left(\mathrm{BP}_{\mathrm{ND}}\right)$ which were estimated using the simplified reference tissues model (SRTM) [46] and a cerebellar cortex (excluding vermis) reference region.

\section{Cue reactivity}

The cue exposure paradigm was modified from a previously validated procedure [47]. During this procedure, participants were seated in a room with instruction provided through a computer and they were observed through a 2-way mirror. The session began with a 3-min relaxation period where participants were acclimated to the environment. After this, participants underwent 4 cue exposure trials. Each trial consisted of the introduction of a cup containing a beverage as well as the associated commercially labelled bottle under a cover, so the participant remained blinded to the content of the cue until instructed. The cues for the neutral conditions were a glass of water and a water bottle, while the cues for the alcohol condition was the participants preferred alcohol beverage (e.g., wine, beer, hard liquor; previously collected) and associated container. When instructed, participants lifted the cover and interacted with the cue. Participants were told to hold and smell the cup when they heard a high pitch tone and place the cup down when they heard a low pitch tone. There were 13 signals to smell the liquid contents in each 3-min trial. There were 2 neutral and 2 alcohol condition trials each separated by 3-min relaxation periods, for a total of 4 cue trials. To avoid carry over effects $[48,49]$, the neutral cue condition occurred before the alcohol condition for all participants. After each trial and the acclimation period, participants completed the Alcohol Urge Questionnaire (AUQ) [50] and an urge question on an 8 point likert scale ("How strong is your urge to drink alcohol right now?"). Outcome measures were AUQ and urge question scores that were averaged across the 2 individual cue trials for each cue condition.

\section{Intravenous self-administration}

The intravenous self-administration (IVASA) procedure used here was consistent with our other studies using an IVASA paradigm [51, 52], but modified to involve a progressive ratio (PR) schedule [53]. Participants were given the opportunity to intravenously infuse alcohol on a PR schedule using the Computer Assisted Infusion system (CAIS)[54], which uses a physiologically-based pharmacokinetic (PBPK) model to calculate infusion rates to achieve equivalent increments in BrAC across subjects. Participants were instructed to abstain from alcohol for $24 \mathrm{~h}$ prior to the procedure and had to provide a BrAC reading of $0.0 \mathrm{mg} \%$ for the procedure to begin. Nursing staff inserted an indwelling catheter, and participants were subsequently seated on a reclining chair in front of a computer. Participants were instructed to push a button to obtain alcohol during the 180-min session. Alcohol was delivered by a CAIS initiated infusion of $6 \%(\mathrm{v} / \mathrm{v})$ alcohol-in-saline solution that targeted an incremental $\mathrm{BrAC}$ increase of $10 \mathrm{mg} \%$ over $2.5 \mathrm{~min}$ after each completed work set.

Participants began the 180 -min session with a 13.5 -minute-long priming phase. The priming phase served as a period to familiarize the participants with the infusion process while exposing all participants to 3 infusions (requiring 6 button presses each) aimed at reaching a BrAC of $30 \mathrm{mg} \%$. After this phase, participants were free to choose if they wanted more alcohol, for which they needed to complete additional "work sets" (a total number of button presses), with each alcohol infusion requiring larger work sets (Supplementary Table 1).There was a maximum of 20 earnable infusions (total button presses required $=27,420$ ) throughout the session. When infusions were not in progress, the software specified a descending BrAC rate of $-1 \mathrm{mg} \%$ per min. There was a safety ceiling of $150 \mathrm{mg} \%$, such that further alcohol delivery was prevented until the subsequent infusion would not cause the participant to exceed this threshold. This procedure allows for more control over BrAC levels while eliminating alcohol associated environmental cues for more precise investigation of motivation to consume alcohol [54].

Upon completion of the session, medical staff disconnected the participant from the infusion pumps and removed the catheter. Participants remained in the lab until their BrAC dropped to below 20 $\mathrm{mg} \%$. Outcome measures for this session were peak BrAC, BrAC area under the curve (AUC), completed work sets, and cumulative button presses.

\section{Self-report measures}

Throughout the study, participants completed a battery questionnaire. Alcohol use and dependence severity was measured by the 10-item alcohol use disorder identification test (AUDIT; covers alcohol consumption, drinking behaviour and alcohol-related problems) [55] and the 25item alcohol dependence scale (ADS; covers loss of behavioural control over alcohol consumption, obsessive-compulsive drinking, and alcohol withdrawal symptoms)[56]. Separate from the cue-reactivity session, alcohol craving was assessed using the 5-item single-factor Penn Alcohol craving scale (PACS; covers craving characteristics, e.g., how often, how long, how strong)[57]. Scores for each measure were calculated using validated methods.

The relative reinforcing effect of alcohol was examined using the alcohol purchase task (APT) $[58,59]$. The APT was collected as part of battery of questionnaires mentioned above. Five outcomes derived from the APT were of interest for the present study: intensity, breakpoint, maximum expenditure (Omax), price associated with Omax (Pmax), and alpha (elasticity across the demand curve). As described in a recent methodological review of the APT [60], intensity describes consumption at no cost (amount of alcohol purchased at \$0.00). Breakpoint reflects the first price to reduce consumption to 0 (if this point was not reached, breakpoint was assigned a value of the highest cost-\$15.00). Omax is calculated as the greatest single expenditure across the demand curve and Pmax was calculated as the price associated with this point of greatest expenditure [50]. Finally, alpha reflects the rate of change in elasticity across the demand curve (fit with an exponentiated function, as described elsewhere [61]). In other words, alpha reflects observed changes in the sensitivity of hypothetical consumption of alcohol as a function of price, with lower values of alpha corresponding to greater demand for alcohol [62]. Finally, alpha reflects elasticity across the demand curve (fit with an exponentiated function, as described elsewhere [61]).

\section{Data analysis}

$\left[{ }^{11} \mathrm{C}\right]-(+)-\mathrm{PHNO} \mathrm{BP}_{\mathrm{ND}}$ values were analyzed using a group $\mathrm{x}$ ROI multivariate ANOVA (MANOVA) with group (AUD, HC) as independent variables while ROIs (LST, AST, SMST, SN, GP, VP) were dependent variables. Follow-up univariate ANOVAs where conducted to investigate regionspecific group differences in $\left[{ }^{11} \mathrm{C}\right]-(+)-\mathrm{PHNO} \mathrm{BP}_{\mathrm{ND}}$. Bivariate correlation analyses were conducted to investigate the relationship between $\left[{ }^{11} \mathrm{C}\right]$ $(+)$-PHNO $\mathrm{BP}_{\mathrm{ND}}$ in AUD participants alone and the various clinical (demographic, questionnaire) as well as laboratory measures (craving, IVASA measures).

In the cue-reactivity paradigm, differences scores of all outcomes (AUQ and urge question) were calculated for both the alcohol and neutral condition (i.e., condition minus baseline). Conditions were compared to each other using $t$ tests. The delta between alcohol and neutral difference scores were used in the correlation analysis to explore relationship between cue-elicited craving and $\left[{ }^{11} \mathrm{C}\right]-(+)-\mathrm{PHNO} B \mathrm{P}_{\mathrm{ND}}$.

Prior to analysis the APT data were cleaned according to a 3-criterion algorithm proposed by Stein and colleagues [63]. This algorithm detects cases that violate the assumptions of trend (a global non-negligible reduction in consumption from the first to last price), bounce (less than $10 \%$ price-to-price increases in consumption), and reversals from zero (consumption subsequent to a zero-value consumption at a given lower price) [52]. Of the 16 participants that completed this questionnaire (note the varying \# of subjects in different analysis in the "AUD subjects" section of the results), 14 subjects were retained for this analysis: one case was removed for violating the trend criterion (invariant consumption across all prices) and one case for violating the reversal from zero criterion. The primary outcomes derived from the APT data, as noted above, were intensity, breakpoint, Omax, Pmax, and alpha (where lower levels of alpha reflect higher demand for alcohol [62]). These outcomes were derived using the beezdemand $\mathrm{R}$ package [62]. Equations were fit using the exponentiated approach described elsewhere [61].

Bonferroni's corrections were applied on all multiple comparisons which were applicable in all ROI analysis (corrected significance level $p=0.0083$ ). For all other analysis (e.g., validation data) results were considered significant at $p<0.05$ (SPSS ver. 25.0).

\section{RESULTS}

\section{Participants}

A total of 17 AUD subjects were scanned and compared to $18 \mathrm{HCs}$. These groups were matched on age (AUD: $42.35 \pm 12.39$, HC: $40.72 \pm 10.68$ ), sex (AUD: $76.5 \%$ male, HC: $77.8 \%$ male), smoking status (AUD: $30 \%$ smokers, HC: $39 \%$ smokers) and race (AUD and 
Table 1. This table describes AUD related characteristics and PET scan parameters for the AUD group.

$\begin{array}{ll}\text { AUD group measures } & \text { Mean } \pm \text { SD } \\ \text { AUD/drinking characteristics } & \\ \text { Weekly average drinks } & 67.08 \pm 36.29 \\ \text { \# of heavy drinking days (out of previous } 90 \text { days) } & 41.27 \pm 28.4 \\ \text { \# of alcohol abstinent days prior to PET scan } & 6.59 \pm 4.14 \\ \text { \# of endorsed DSM-5 AUD criteria } & 4.12 \pm 1.73 \\ \text { AUD severity (DSM-5 classification) } & \text { Mild }=3 \\ & \text { Moderate }=8 \\ & \text { Severe }=6 \\ \text { AUDIT score } & 20 \pm 6.30 \\ \text { Alcohol dependence scale } & 14.5 \pm 6.60 \\ \text { \# of smokers } & n=5(30 \%) \\ \text { FTND score } & 2.2 \pm 1.92 \\ \text { PET scan parameters } & \\ \text { Specific activity ( } \mathrm{mCi} / \mu \text { mole) } & 1121.97 \pm 267.60 \\ \text { Amount injected }(\mathrm{mCi}) & 9.23 \pm 1.00 \\ \text { Injected mass }(\mu \mathrm{g} / \mathrm{kg}) & 0.027 \pm 0.007 \\ \text { PET scan parameters are measured at the time of injection. } \\ \text { AUD alcohol use disorder, SD standard deviation, FTND Fagerstrom Nicotine } \\ \text { Dependence Test, } \mathrm{mCi} \text { millicurie, } \mu \text { mole micromole, } \mu g \text { microgram. }\end{array}$

HC: $100 \%$ white). Chi-square analysis and independent samples $t$ tests showed that HCs did not differ from AUD subjects in these measures. Alcohol related characteristics and PET scan parameters for the AUD sample are described in Table 1. AUD subjects met an average of $4.12 \pm 1.73$ DSM-5 AUD criteria (i.e., moderate AUD). Of note, there were different sample sizes for different analyses below due to external complications with the study (e.g., COVID19) which resulted in some participants not completing certain study procedures (e.g., IVASA, questionnaires, etc.). Therefore, there were 35 total subjects in the $\left[{ }^{11} \mathrm{C}\right]-(+)-\mathrm{PHNO}$ group analysis (17 AUD [all 17 also used in clinical correlations], $18 \mathrm{HCs}$ ), 16 AUD participants included in the cue-reactivity analysis, and 9 AUD subjects in the IVASA analysis.

$\left[{ }^{11} \mathrm{C}\right]-(+)-\mathrm{PHNO} \mathrm{BP}_{\mathrm{ND}}(n=35)$

One-way group (2 levels) x ROI (6 levels) MANOVA revealed a significant group difference when ROls were jointly considered (Wilk's $\Lambda=.58, F(6,28)=3.33, p=0.013, \eta_{p}^{2}=0.42 ;$ Fig. 1). As Box's $M(47.63)$ was not significant $(p=0.013)$ at an alpha level of $p=$ 0.001 [64], the assumption of homogeneity of covariance is met. While binding levels in the AUD group were lower than in HCs in most ROIs (SN, VP, GP, AST, SMST; percent difference range: -1.6 to $-16.1 \%)$, they were higher in the LST $(4.0 \%$; Table 2$)$. This suggests that AUD subjects demonstrated lower $\left[{ }^{11} \mathrm{C}\right]-(+)-\mathrm{PHNO}$ $\mathrm{BP}_{\mathrm{ND}}$ than HCs when looking at the examined ROls generally. Follow-up univariate ANOVAs were conducted for each ROI with a Bonferroni adjusted significance level of $p=0.0083$ to account for multiple comparisons. These univariate tests revealed that while $\left[{ }^{11} \mathrm{C}\right]-(+)-\mathrm{PHNO} \mathrm{BP}_{\mathrm{ND}}$ in the SMST was lower in AUD subjects $(\mathrm{M} \pm$ SD; $2.11 \pm 0.47)$ compared to HCs $(2.41 \pm 0.35)$, this did not reach the Bonferroni adjusted significance level $(F(1,33)=4.49, p=$ $\left.0.042, \eta_{p}^{2}=0.12\right)$. There were no group difference in $\left[{ }^{11} \mathrm{C}\right]$ $(+)-\mathrm{PHNO} \mathrm{BP}_{\mathrm{ND}}$ in any other ROI. These pattern of results were maintained when age and sex were included as covariates in secondary analysis (MANCOVA: Wilk's $\Lambda=.57, F(6,26)=3.36, p=$ $0.016, \eta_{\mathrm{p}}^{2}=0.43$ ).

For increased comparability to other PET papers, we also conducted a repeated-measures ANOVA (RMANOVA) with ROIs (6 levels) as within-subject factors and group (2 levels) as a betweensubject factor. Because the sphericity assumption was violated,

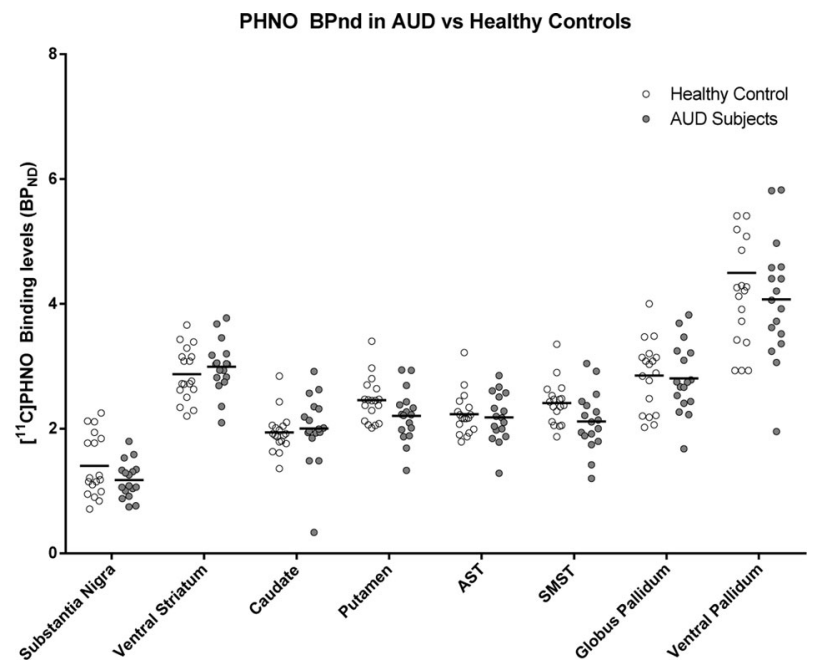

Fig. 1 This figure compares the $\left[{ }^{11} \mathrm{C}\right]-(+)-\mathrm{PHNO} \mathrm{BP}_{\mathrm{ND}}$ of AUD subjects to those of healthy controls. A one-way MANOVA revealed significantly lower binding in AUD subjects compared to healthy controls when looking at all ROls jointly (Wilk's $\Lambda=.58, F(6,28)=3.33$, $p=0.013, \eta_{p}^{2}=0.42$ ). There were no region-specific differences in binding levels between groups. $\mathrm{BP}_{\mathrm{ND}}$ nondisplaceable binding potential, AST associate striatum, SMST sensorimotor striatum.

Greenhouse-Geisser results are reported here. The results showed no difference between groups $(F(1.519,50.116)=0.938, p=0.375$, $\left.\eta_{p}^{2}=0.028\right)$. This further corroborated the finding that DRD3 levels are not elevated in AUD subjects compared to HCs. This pattern of results were maintained when age (covariate) and sex (betweensubject variable) were included in the RMANOVA.

\section{Cue-elicited craving $(n=16)$}

Main effects. Paired sample $t$ test showed that alcohol cues elicited greater craving than neutral cues, observed in both the AUQ $(t(15)=6.612, p<0.001$; Fig. $2 \mathrm{~A})$ and the urge question $(t$ $(15)=5.310, p<0.001)$ while controlling for baseline craving.

Correlations. There was a positive correlation between AUQ measured alcohol (minus neutral) cue elicited craving and $\left[{ }^{11} \mathrm{C}\right]-$

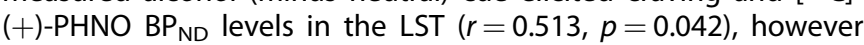
this did not withstand Bonferroni corrections (corrected significance level $p=0.0083$; Fig. 2D). There were no correlations seen with the single urge question.

\section{IVASA $(\boldsymbol{n}=\mathbf{9})$}

Alcohol consumption. During this session, participants performed an average $( \pm S D)$ of $5703.22 \pm 4611.98$ button presses and completed an average of $12 \pm 5.05$ work sets (i.e., received an average of 12 infusions). This resulted in an average peak BrAC of $64.56 \pm 39.19 \mathrm{mg} \%$ across all participants at the $60-\mathrm{min}$ (Fig. 3A).

Correlations. There were no correlations observed between IVASA outcome measures (peak BrAC, BrAC AUC, \# of work sets, \# of button presses) and binding in any ROls (Fig. 3B-D).

\section{Clinical measures}

Correlations. There were no significant correlations between any of the clinical measures analyzed (i.e., daily drink average, \# of heavy drinking episodes, PACS, AUDIT, AUD severity, and ADS) and $\left[{ }^{11} \mathrm{C}\right]-(+)-\mathrm{PHNO} \mathrm{BP}_{\mathrm{ND}}$ that withstood Bonferroni corrections. In the APT $(n=14)$, alpha was positively correlated with binding in the SN $(r=0.66, p=0.0080)$ after Bonferroni corrections, suggesting that AUD participants with lower $\left[{ }^{11} \mathrm{C}\right]-(+)-\mathrm{PHNO} \mathrm{BP}_{\mathrm{ND}}$ in the 
Table 2. This table describes the $\left[{ }^{11} \mathrm{C}\right]-(+)-P H N O$ BP ${ }_{\mathrm{ND}}$ values for the AUD and healthy control groups in all ROls.

\begin{tabular}{|lllll} 
Brain regions of interest & $\begin{array}{l}\text { Healthy controls }(\mathbf{n}= \\
\mathbf{1 8})\end{array}$ & AUD $(\boldsymbol{n}=\mathbf{1 7})$ & $\begin{array}{l}\boldsymbol{\%} \text { Difference (AUD } \\
\left.\mathbf{B P}_{\mathbf{N D}}\right)\end{array}$ & $\begin{array}{l}\boldsymbol{t} \text { test }(\boldsymbol{p} \text { values; corrected significance level } \\
\boldsymbol{p}=\mathbf{0 . 0 0 8 3})\end{array}$ \\
\hline Limbic striatum & $2.87 \pm 0.42$ & $2.99 \pm 0.42$ & 4.0 & 0.42 \\
\hline Associate striatum & $2.23 \pm 0.34$ & $2.18 \pm 0.39$ & -2.3 & 0.68 \\
\hline Sensorimotor striatum & $2.41 \pm 0.35$ & $2.11 \pm 0.47$ & -12.3 & 0.04 \\
\hline Globus pallidum & $2.85 \pm 0.56$ & $2.80 \pm 0.56$ & -1.6 & 0.82 \\
\hline Ventral pallidum & $4.5 \pm 1.73$ & $4.07 \pm 0.97$ & -9.4 & 0.38 \\
\hline Substantia nigra & $1.4 \pm 0.50$ & $1.18 \pm 0.29$ & -16.1 & 0.11
\end{tabular}

AUD subjects had lower $\mathrm{BP}_{\mathrm{ND}}$ in all ROls except for the LST, however there were no differences that survived Bonferroni corrections. $A U D$ alcohol use disorder, $\mathrm{BP}_{\mathrm{ND}}=$ nondisplaceable binding potential.

A)

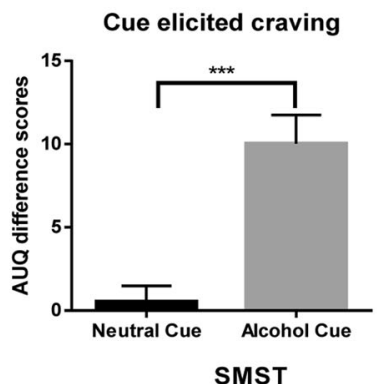

C)

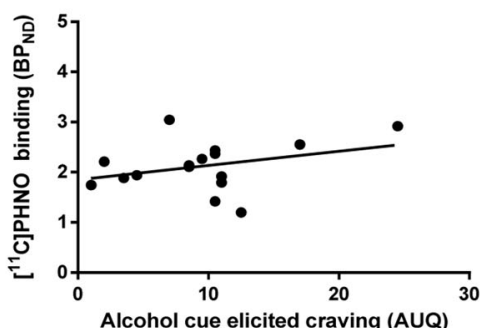

B)

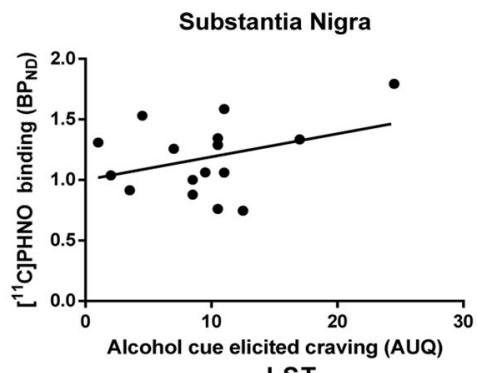

D)

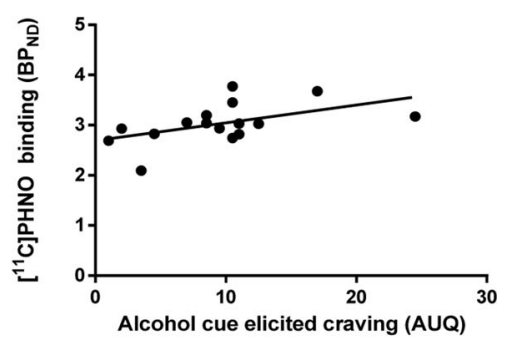

Fig. 2 This panel of graphs show the main effects of alcohol craving and the correlations between alcohol-cue-induced craving and [ ${ }^{11} \mathrm{C}$ ](+)-PHNO BP ND. A compares cue elicited craving in both the neutral and alcohol cue condition, the alcohol cues eliciting greater craving than neutral cues $(\mathrm{t}(15)=6.612, p<0.0001)$. B-D graph the correlation analysis between $\left[{ }^{11} \mathrm{C}\right]-(+)-\mathrm{PHNO} \mathrm{BP}_{\mathrm{ND}}$ in different ROls and alcohol cueelicited craving. These ROls were chosen to depict DRD3-rich (SN), DRD2-rich (SMST) and DRD2/3 mixed areas (LST). There were no statistically significant correlations except for in the LST which showed a significant positive correlation with binding levels $(r=0.513, p=0.042)$, though this did not survive Bonferroni corrections (corrected significance level $p=0.0083$ ). AUQ Alcohol Urge Questionnaire. ${ }^{* * *}=p$ value $<0.001$.

SN had lower alpha levels, demonstrating higher demand for alcohol (Fig. 3E).

\section{DISCUSSION}

This is the first study using $\left[{ }^{11} \mathrm{C}\right]-(+)-$ PHNO to show reduced DRD2/3 levels in AUD subjects compared to controls. Specifically, the main finding was a significant group difference in $\left[{ }^{11} \mathrm{C}\right]-$ $(+)-\mathrm{PHNO} \mathrm{BP}_{\mathrm{ND}}$ between AUD subjects and HCs when looking at examined ROls generally. An inspection of $\mathrm{BP}_{\mathrm{ND}}$ values showed that AUD subjects had lower binding $(2-16 \%)$, reflecting lower receptor levels, in $83 \%$ of the examined ROls compared to HCs. That said, analysis of individual ROls showed no significant group difference in region-specific receptor levels. Contrary to our hypothesis, these results suggest a non-region-specific reduction in DRD2/3 levels in early abstinent AUD subjects. Specifically, we did not observe increased $\left[{ }^{11} \mathrm{C}\right]-(+)-P H N O$ binding in DRD3-rich areas $(\mathrm{SN}, \mathrm{VP}, \mathrm{GP})$, suggesting that DRD3 are not upregulated in early abstinent AUD subjects. We also did not observe regionspecific reductions of $\left[{ }^{11} \mathrm{C}\right]-(+)-P H N O$ binding in DRD2-rich areas (AST, SMST) or DRD2/3 mixed areas (LST). In addition, we did not find an association between binding levels and alcohol cueinduced craving or IVASA measures that withstood corrections. These results suggest that dopamine receptor levels are reduced in AUD subjects in early abstinence but provide no evidence regarding region-specific reductions or associations between receptor levels and our measures of AUD phenotypes. Therefore, these results warrant further investigation.

The primary findings here demonstrate lower $\left[{ }^{11} \mathrm{C}\right]-(+)-\mathrm{PHNO}$ $\mathrm{BP}_{\mathrm{ND}}$ in AUD compared to HCs in the examined ROls combined. We did not observe difference in receptor levels when considering DRD3-rich areas (SN,GP, VP), suggesting a lack of DRD3 upregulation in early abstinent AUD subjects. This is inconsistent with previous preclinical research that have demonstrated increased DRD3 expression in the striatum of rats [27] as well as in the dorsal striatum of mice [28] following voluntary alcohol intake. Animal research suggests that chronic alcohol intake may promote increases in DRD3 expression, therefore, one would expect similar trends in AUD subjects, who chronically consume alcohol. Yet, while contrary to preclinical research, our findings are consistent with the previous $\left[{ }^{11} \mathrm{C}\right]-(+)$-PHNO PET study that also found a lack of increased DRD3 levels in all AUD brain regions when examining $\mathrm{BP}_{\mathrm{ND}}[40]$. The previous study did find an elevation of [11 C](+)-PHNO volume of distribution in the hypothalamus of subjects with AUD, however, there was no significant elevation while evaluating $[11 \mathrm{C}]-(+)-$ PHNO binding potential. Due to the design of our study, we were unable to assess $\left[{ }^{11} \mathrm{C}\right]-(+)-\mathrm{PHNO}$ volume of distribution. In addition, our imaging analysis template did not 


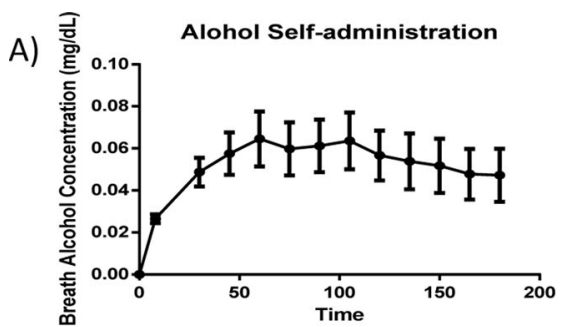

B)

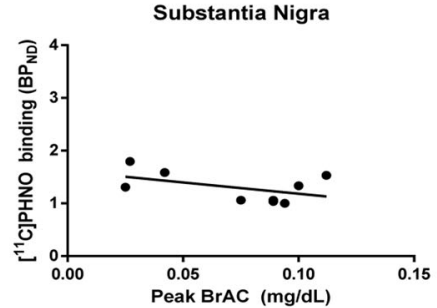

C)

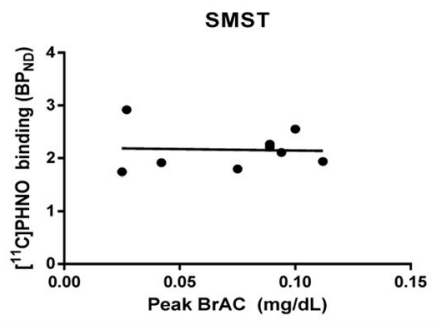

D)

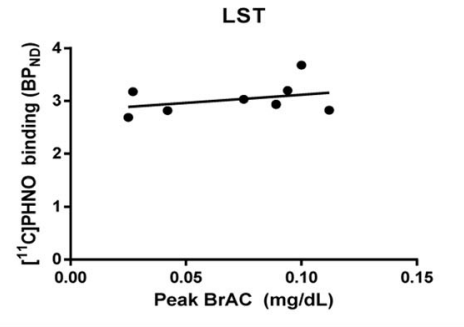

E) Substantia Nigra binding and alcohol demand correlation

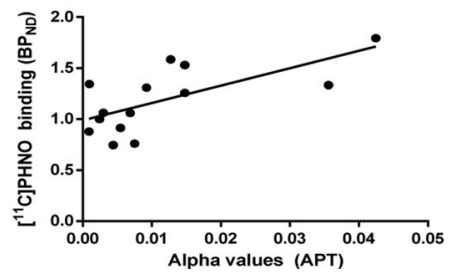

Fig. 3 This panel of graphs shows IVASA alcohol consumption patterns, the correlation between motivation to consume alcohol and

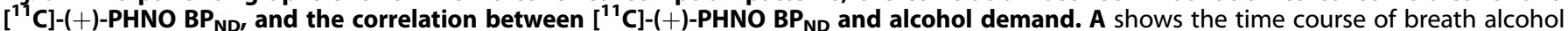
concentration (BrAC) throughout the intravenous self-administration session. During this session, participants achieved an average BrAC of $0.65 \pm 0.39 \mathrm{mg} / \mathrm{dL}$ at around the 60 -min mark. B-D graph the correlation analysis between $\left[{ }^{11} \mathrm{C}\right]-(+)-\mathrm{PHNO}$ BP $\mathrm{ND}$ in different ROls and peak BrAC achieved during the session. These ROls were chosen to depict DRD3-rich (SN), DRD2-rich (SMST) and DRD2/3 mixed areas (LST). There were no statistically significant correlations between peak BrAC and binding in any ROI. $\mathbf{E}$ This graph depicts the correlation between $\left[{ }^{11} \mathrm{C}\right]-$ $(+)-\mathrm{PHNO} \mathrm{BP}_{\mathrm{ND}}$ and the alpha values of the alcohol purchase task (APT). There is a significant positive correlation between these measures such that AUD subjects with lower $\left[{ }^{11} \mathrm{C}\right]-(+)-\mathrm{PHNO} \mathrm{BP}_{\mathrm{ND}}$ in the $\mathrm{SN}$ display lower alpha values $(r=0.66, p=0.0080)$.

include hypothalamus delineation. Therefore, we cannot rule out the existence of group differences in DRD3 levels based on the divergent methods used in the current study.

Considering similar findings in both PET studies for comparable ROI, the increased DRD3 expression seen particularly in striatal areas of animal models $[27,28]$ may not translate to human AUD subjects. Furthermore, our results show that AUD subjects demonstrated a $16.1 \%$ decrease in $\left[{ }^{11} \mathrm{C}\right]-(+)-\mathrm{PHNO} \mathrm{BP}_{\mathrm{ND}}$ in the SN (87-100\% reflective of DRD3 levels $[38,39])$, suggesting a decrease in DRD3 levels, though this did not reach significance. This is in line with previous studies that have used DRD2/3 radioligands including $\left[{ }^{11} \mathrm{C}\right] \mathrm{FLB} 457$ [65] and $\left[{ }^{18} \mathrm{~F}\right]$ fallypride [66] that showed non-significantly decreased receptor binding in the SN of AUD subjects compared to healthy controls. Therefore, not only did we fail to observe DRD3 upregulation, but there may be evidence to support a downregulation of DRD3 in early abstinent AUD. The present study adds to the literature by demonstrating that this lack of DRD3 upregulation is unlikely due to a potential recovery of DRD3 levels upon abstinence as our sample was scanned with an average $( \pm S D)$ of $6.59 \pm 4.14$ days of abstinence (in contrast to the $415 \pm 254$ days of abstinence in previous PET study [40]).

On the other hand, our results of reduced $\left[{ }^{11} \mathrm{C}\right]-(+)-\mathrm{PHNO} B \mathrm{P}_{\mathrm{ND}}$ when considering all examined ROI together are more in line with previous PET literature investigating DRD2 expression in AUD. PET studies using antagonist radiotracers (e.g., $\left[{ }^{11} \mathrm{C}\right]$ raclopride, $[12,13,67,68]\left[{ }^{18} \mathrm{~F}\right]$ desmethoxyfallypride $\left.[14,69]\right)$ have typically reported lower striatal DRD2/3 levels in AUD subjects compared to healthy controls. While we did not confirm our hypothesis of region-specific reductions in DRD2-rich areas (LST, AST, SMST [39]), we did observe statistically significant global DRD2/3 reductions in AUD subjects with a $12.3 \%$ reduction in the SMST (region-specific reduction in SMST did not reach significance). Taken together with the inspection of $\left[{ }^{11} \mathrm{C}\right]-(+)-\mathrm{PHNO} \mathrm{BP}_{\mathrm{ND}}$ in DRD3-rich areas, these results add to the literature by replicating reduced DRD2/3 levels in AUD subjects as seen in previous studies, while also demonstrating that DRD3 levels are not upregulated and may potentially be downregulated.

There is the argument that since DRD2 and DRD3 are colocalized, regulation of one receptor subtype (e.g., DRD3 upregulation) may be masked by the regulation of another in the opposite direction (e.g., DRD2 downregulation). While our study did not address this directly, a previous PET study found that occupancy of a selective DRD3 antagonist (GSK598809) was similar in both AUD and control patients [40], suggesting that the ratio of DRD2/3 in various $\mathrm{ROI}$ is unchanged under conditions of chronic alcohol consumption. This makes the argument of compensatory DRD2 reduction alongside DRD3 increases unlikely.

The current study found that alcohol cues elicit significantly greater cravings than neutral cues, and craving increases were positively associated with $\left[{ }^{11} \mathrm{C}\right]-(+)-$ PHNO binding in the LST, however this was not significant after Bonferroni corrections. Given that $\left[{ }^{11} \mathrm{C}\right]-(+)-$ PHNO binding in the LST is predominated by DRD2 (26-39\% reflective of DRD3 levels) [38, 39], and previous human PET studies have reported a negative association between alcohol-cue-induced craving and DRD2 levels [14, 15], these findings seem contradictory. The previous PET studies used different methodologies (e.g., pictorial stimuli for cue-reactivity) 
and are limited in number, which adds difficulty in interpreting the current findings. Therefore, future studies should aim to illuminate the relative contributions of DRD2 and DRD3 levels in human alcohol craving behaviour.

Most measures from our IVASA paradigm were not associated with $\left[{ }^{11} \mathrm{C}\right]-(+)-\mathrm{PHNO}$ binding. $\left[{ }^{11} \mathrm{C}\right]-(+)-\mathrm{PHNO}$ binding in $\mathrm{SN}$ (almost exclusively represents DRD3 levels $[38,39]$ ) was positively associated with alpha (lower alpha reflects higher demand for alcohol [62]) in the APT. This suggests that those with lower DRD3 levels in the SN demonstrated higher demand for alcohol. This supports our overall findings of lower DRD2/3 (and specifically a non-significant $16.1 \%$ decreased in SN DRD3) levels in AUD subjects compared to HCs and suggests that lower DRD3 may be associated with increased demand for alcohol, which may be a driving factor in the increased alcohol consumption that is characteristic of AUD subjects. The direction of this finding is somewhat unanticipated based on preclinical literature that shows an association between increased DRD3 expression and greater alcohol use $[27,28]$. This inconsistency may be due to a difference between the animal and human condition, further suggesting that the relationship between DRD3 and the reinforcing effects of alcohol seen in animals may not translate to humans. Given our sample, future research should aim to replicate this with larger and more severe sample populations.

This is the first study to explore the association between human laboratory measures of AUD phenotypes (alcohol motivation and cue-induced craving) and $\left[{ }^{11} \mathrm{C}\right]-(+)-$ PHNO binding, yet the results should be considered within the context of the study limitations. First, while our sample size is comparable to other PET studies comparing drug users to health controls $[13,67,70]$, we were likely underpowered to detect the expected correlations between AUD phenotypes and receptor levels. Second, our sample may have less severe AUD compared to some other studies. Our sample met an average of $4.12 \pm 1.73$ DSM-5 AUD criteria (i.e., moderate AUD) and were recruited from the local community. Other PET studies that investigated dopamine receptor regulation in AUD subjects have recruited from outpatient treatment programs and other therapeutic communities $[13,67,70]$. The qualitative difference in AUD characteristics between sample populations may result in different alcohol related behaviours, which may in turn affect receptor levels. Third, subjects were asked to abstain from cigarette smoking overnight and therefore may have been in nicotine withdrawal during the PET scan. Because we did not measure nicotine withdrawal specifically, we cannot rule out the possibility of an effect on $\left[{ }^{11} \mathrm{C}\right]-(+)-$ PHNO binding. Fourth, it has been shown that factors like impaired control over alcohol and impulsivity may affect alcohol use[71, 72]. The current study did not investigate these factors; therefore it is unclear how those factors may affect our alcohol consumption in the IVASA procedure and the correlations to $\left[{ }^{11} \mathrm{C}\right]-(+)-\mathrm{PHNO}$ binding. Finally, several brain regions afflicted by volume loss have been reported in conditions associated with AUD [73]. Relatedly, the use of a SRTM model here and the potential for group differences in $\left[{ }^{11} \mathrm{C}\right]-(+)-\mathrm{PHNO}$ binding in the cerebellum (the reference region) presents a potential confound that may contribute to the observed global reductions DRD2/3 levels. It is possible that binding in the cerebellum is negligible however, we cannot rule out the possibility of group differences in $\left[{ }^{11} \mathrm{C}\right]-(+)$-PHNO binding in the reference region. Therefore, it is unknown whether brain tissue volume loss or group differences in cerebellar tissue volume affected receptor levels or $\left[{ }^{11} \mathrm{C}\right]-(+)-\mathrm{PHNO}$ binding values observed here.

In conclusion, this study used PET imaging with $\left[{ }^{11} \mathrm{C}\right]-(+)-\mathrm{PHNO}$ to explore DRD3 regulation and function in AUD subjects. We found that early abstinent AUD subjects had lower non-region-specific $\left[{ }^{11} \mathrm{C}\right]-(+)-\mathrm{PHNO}$ binding, reflecting lower DRD2/3 levels, compared to healthy controls. This replicates findings from a previous PET studies and extends the literature by suggesting a lack of increased DRD3 levels in early abstinence AUD. In addition, while DRD3 levels were not associated with our measures of alcohol motivation, there was an uncorrected positive correlation between DRD2/3 levels in the LST and alcohol cue-induced craving. As this finding did not survive Bonferroni corrections, it warrants further investigation with a larger sample size. Future studies should address the limitations presented here and aim to validate the relationship between DRD3s and AUD phenotypes in humans.

\section{REFERENCES}

1. Alcohol GBD, Drug C. Use The global burden of disease attributable to alcohol and drug use in 195 countries and territories, 1990-2016: a systematic analysis for the Global Burden of Disease Study 2016. Lancet Psychiatry. 2018;5:987-1012.

2. Peacock A, Leung J, Larney S, Colledge S, Hickman M, Rehm J, et al. Global statistics on alcohol, tobacco and illicit drug use: 2017 status report. Addiction. 2018;113:1905-26.

3. Vujanovic AA, Meyer TD, Heads AM, Stotts AL, Villarreal YR, Schmitz JM. Cognitive-behavioral therapies for depression and substance use disorders: An overview of traditional, third-wave, and transdiagnostic approaches. Am J Drug Alcohol Abus. 2017:43:402-15.

4. Chukwueke CC, Le Foll B. The human laboratory and drug development in alcohol use disorder: recent updates. Methods Mol Biol. 2019;2011:195-219.

5. Franck J, Jayaram-Lindstrom N. Pharmacotherapy for alcohol dependence: status of current treatments. Curr Opin Neurobiol. 2013;23:692-9.

6. Litten RZ, Egli M, Heilig M, Cui C, Fertig JB, Ryan ML, et al. Medications development to treat alcohol dependence: a vision for the next decade. Addict Biol. 2012;17:513-27.

7. Ma H, Zhu G. The dopamine system and alcohol dependence. Shanghai Arch Psychiatry. 2014;26:61-8.

8. Jonsson S, Ericson M, Soderpalm B. Modest long-term ethanol consumption affects expression of neurotransmitter receptor genes in the rat nucleus accumbens. Alcohol Clin Exp Res. 2014;38:722-9.

9. Feltmann $\mathrm{K}$, et al. Effects of long-term alcohol drinking on the dopamine $d 2$ receptor: gene expression and heteroreceptor complexes in the striatum in rats. Alcohol Clin Exp Res. 2018;42:338-51.

10. Repo E, Kuikka JT, Bergstrom KA, Karhu J, Hiltunen J, Tiihonen J. Dopamine transporter and D2-receptor density in late-onset alcoholism. Psychopharmacol (Berl). 1999;147:314-8.

11. Guardia J, Catafau AM, Batlle F, Martin JC, Segura L, Gonzalvo B. et Striatal dopaminergic $D(2)$ receptor density measured by [(123)I]iodobenzamide SPECT in the prediction of treatment outcome of alcoholdependent patients. Am J Psychiatry. 2000;157:127-9.

12. Hietala J, West C, Syvalahti E, Nagren K, Lehikoinen $P$, Sonninen $P$, et al. Striatal D2 dopamine receptor binding characteristics in vivo in patients with alcohol dependence. Psychopharmacol (Berl). 1994;116:285-90.

13. Volkow ND, Wang GJ, Fowler JS, Logan J, Hitzemann R, Ding YS, et al. Decreases in dopamine receptors but not in dopamine transporters in alcoholics. Alcohol Clin Exp Res. 1996;20:1594-8.

14. Heinz A, Siessmeier T, Wrase J, Hermann D, Klein S, Grusser SM, et al. Correlation between dopamine $D(2)$ receptors in the ventral striatum and central processing of alcohol cues and craving. Am J Psychiatry. 2004;161:1783-9.

15. Heinz A, Dettling M, Kuhn S, Dufeu P, Graf KJ, Kurten I, et al. Blunted growth hormone response is associated with early relapse in alcohol-dependent patients. Alcohol Clin Exp Res. 1995;19:62-5.

16. Trick L, Butler K, Chukwueke C, Di Ciano P, Ibrahim C, Rubin-Kahana DS, et al. Abnormalities of Neurotransmission in Drug Addiction. In: Psychiatry OA, Dierckx RA, de Vries EFJ, van Waarde A, Sommer IE, editors. PET and SPECT. Cham: Springer; 2021. p. 653-712.

17. Gurevich EV, Joyce JN. Distribution of dopamine D3 receptor expressing neurons in the human forebrain: comparison with D2 receptor expressing neurons. Neuropsychopharmacology. 1999;20:60-80.

18. Murray AM, Ryoo HL, Gurevich E, Joyce JN. Localization of dopamine D3 receptors to mesolimbic and D2 receptors to mesostriatal regions of human forebrain. Proc Natl Acad Sci USA. 1994;91:11271-5.

19. Neisewander JL, Fuchs RA, Tran-Nguyen LT, Weber SM, Coffey GP, Joyce JN. Increases in dopamine D3 receptor binding in rats receiving a cocaine challenge at various time points after cocaine selfadministration: implications for cocaineseeking behavior. Neuropsychopharmacology. 2004;29:1479-87.

20. Le Foll B, Schwartz JC, Sokoloff P. Disruption of nicotine conditioning by dopamine $D(3)$ receptor ligands. Mol Psychiatry. 2003;8:225-30.

21. Chiang YC, Chen PC, Chen JC. D(3) dopamine receptors are down-regulated in amphetamine sensitized rats and their putative antagonists modulate the locomotor sensitization to amphetamine. Brain Res. 2003:972:159-67.

22. Mash DC. D3 receptor binding in human brain during cocaine overdose. Mol Psychiatry. 1997;2:5-6. 
23. Segal DM, Moraes CT, Mash DC. Up-regulation of D3 dopamine receptor mRNA in the nucleus accumbens of human cocaine fatalities. Brain Res Mol Brain Res. 1997;45:335-9.

24. Staley JK, Mash DC. Adaptive increase in D3 dopamine receptors in the brain reward circuits of human cocaine fatalities. J Neurosci. 1996;16:6100-6.

25. Boileau I, Nakajima S, Payer D. Imaging the D3 dopamine receptor across behavioral and drug addictions: Positron emission tomography studies with [(11) C]-(+)-PHNO. Eur Neuropsychopharmacol. 2015;25:1410-20.

26. Boileau I, Payer D, Houle S, Behzadi A, Rusjan PM, Tong J, et al. Higher binding of the dopamine D3 receptor-preferring ligand [11C]-(+)-propyl-hexahydro-naphtho-oxazin in methamphetamine polydrug users: a positron emission tomography study. J Neurosci. 2012;32:1353-9.

27. Vengeliene V, Leonardi-Essmann F, Perreau-Lenz S, Gebicke-Haerter P, Drescher $\mathrm{K}$, Gross G, et al. The dopamine D3 receptor plays an essential role in alcoholseeking and relapse. FASEB J. 2006;20:2223-33.

28. Jeanblanc J, He DY, McGough NN, Logrip ML, Phamluong K, Janak PH, et al. The dopamine D3 receptor is part of a homeostatic pathway regulating ethanol consumption. J Neurosci. 2006;26:1457-64.

29. Thanos PK, Katana JM, Ashby CR Jr, Michaelides M, Gardner EL, et al. The selective dopamine D3 receptor antagonist SB-277011-A attenuates ethanol consumption in ethanol preferring $(\mathrm{P})$ and non-preferring (NP) rats. Pharm Biochem Behav. 2005;81:190-7.

30. Heidbreder CA, Andreoli M, Marcon C, Hutcheson DM, Gardner EL, Ashby CR, et al. Evidence for the role of dopamine D3 receptors in oral operant alcohol selfadministration and reinstatement of alcohol-seeking behavior in mice. Addict Biol. 2007:12:35-50.

31. Rice OV, Schonhar CA, Gaal J, Gardner EL, Ashby CR Jr. The selective dopamine D (3) receptor antagonist SB-277011-A significantly decreases binge-like consumption of ethanol in C57BL/J6 mice. Synapse. 2015;69:295-8.

32. Mugnaini M, lavarone L, Cavallini P, Griffante C, Oliosi B, Savoia C, et al. Occupancy of brain dopamine D3 receptors and drug craving: a translational approach. Neuropsychopharmacology. 2013;38:302-12.

33. Murphy A, Nestor LJ, McGonigle J, Paterson L, Boyapati V, Ersche KD, et al. Acute D3 Antagonist GSK598809 Selectively Enhances Neural Response During Monetary Reward Anticipation in Drug and Alcohol Dependence. Neuropsychopharmacology. 2017;42:1049-57.

34. Mogg K, Bradley BP, O'Neill B, Bani M, Merlo-Pich E, Koch A, et al. Effect of dopamine $\mathrm{D}(3)$ receptor antagonism on approach responses to food cues in overweight and obese individuals. Behav Pharm. 2012;23:603-8.

35. Nathan PJ, et al. The effects of the dopamine $D(3)$ receptor antagonist GSK598809 on attentional bias to palatable food cues in overweight and obese subjects. Int J Neuropsychopharmacol. 2012;15:149-61.

36. Lameka K, Farwell MD, Ichise M. Positron emission tomography. Handb Clin Neurol. 2016;135:209-27.

37. Gallezot JD, Beaver JD, Gunn RN, Nabulsi N, Weinzimmer D, Singhal T, et al. Affinity and selectivity of $[(1)(1) C]-(+)-P H N O$ for the D3 and D2 receptors in the rhesus monkey brain in vivo. Synapse. 2012;66:489-500.

38. Searle GE, Beaver JD, Tziortzi A, Comley RA, Bani M, Ghibellini G, et al. Mathematical modelling of $[(1)(1) \mathrm{C}]-(+)-\mathrm{PHNO}$ human competition studies. Neuroimage. 2013;68:119-32.

39. Tziortzi AC, Searle GE, Tzimopoulou S, Salinas C, Beaver JD, Jenkinson M, et al. Imaging dopamine receptors in humans with [11C]-(+)-PHNO: dissection of D3 signal and anatomy. Neuroimage. 2011;54:264-77.

40. Erritzoe D, Tziortzi A, Bargiela D, Colasanti A, Searle GE, Gunn RN, et al. In vivo imaging of cerebral dopamine D3 receptors in alcoholism. Neuropsychopharmacology. 2014;39:1703-12.

41. First, MB, \& Gibbon, M (2004). The Structured Clinical Interview for DSM-IV Axis I Disorders (SCID-I) and the Structured Clinical Interview for DSM-IV Axis II Disorders (SCID-II).

42. Boileau I, Guttman M, Rusjan P, Adams JR, Houle S, Tong J, et al. Decreased binding of the D3 dopamine receptor-preferring ligand [11C]-(+)-PHNO in drugnaive Parkinson's disease. Brain. 2009:132:1366-75.

43. Payer DE, Behzadi A, Kish SJ, Houle S, Wilson AA, Rusjan PM, et al. Heightened D3 dopamine receptor levels in cocaine dependence and contributions to the addiction behavioral phenotype: a positron emission tomography study with [11C]-+-PHNO. Neuropsychopharmacology. 2014;39:311-8.

44. Di Ciano P, Guranda M, Lagzdins D, Tyndale RF, Gamaleddin I, Selby P, et al. Varenicline-induced elevation of dopamine in smokers: a preliminary [(11)C](+)-PHNO PET study. Neuropsychopharmacology. 2016;41:1513-20.

45. Wilson AA, McCormick P, Kapur S, Willeit M, Garcia A, Hussey D, et al. Radiosynthesis and evaluation of [11C]-(+)-4-propyl-3,4,4a,5,6,10b-hexahydro-2Hnaphtho[1,2-b][1,4]oxazin-9-ol as a potential radiotracer for in vivo imaging of the dopamine D2 high-affinity state with positron emission tomography. J Med Chem. 2005;48:4153-60
46. Lammertsma AA, Hume SP. Simplified reference tissue model for PET receptor studies. Neuroimage. 1996;4:153-8.

47. Monti PM, Rohsenow DJ, Rubonis AV, Niaura RS, Sirota AD, Colby SM, et al. Cue exposure with coping skills treatment for male alcoholics: a preliminary investigation. J Consult Clin Psychol. 1993;61:1011-9.

48. Sayette MA, Griffin KM, Sayers WM. Counterbalancing in smoking cue research: a critical analysis. Nicotine Tob Res. 2010;12:1068-79.

49. Monti PM, Binkoff JA, Abrams DB, Zwick WR, Nirenberg TD, Liepman MR. Reactivity of alcoholics and nonalcoholics to drinking cues. J Abnorm Psychol. 1987;96:122-6.

50. Bohn MJ, Krahn DD, Staehler BA. Development and initial validation of a measure of drinking urges in abstinent alcoholics. Alcohol Clin Exp Res. 1995;19:600-6.

51. Wardell JD, Ramchandani VA, Hendershot CS. A multilevel structural equation model of within- and between-person associations among subjective responses to alcohol, craving, and laboratory alcohol self-administration. J Abnorm Psychol. 2015;124:1050-63.

52. Hendershot CS, Claus ED, Ramchandani VA. Associations of OPRM1 A118G and alcohol sensitivity with intravenous alcohol self-administration in young adults. Addict Biol. 2016;21:125-35.

53. Plawecki MH, White K, Kosobud AEK, Grahame N, Zimmermann US, Crabb D, et al. Sex differences in motivation to self-administer alcohol after 2 weeks of abstinence in young-adult heavy drinkers. Alcohol Clin Exp Res. 2018;42:1897-908.

54. Zimmermann US, Mick I, Vitvitskyi V, Plawecki MH, Mann KF, O'Connor S. Development and pilot validation of computer-assisted self-infusion of ethanol (CASE): a new method to study alcohol selfadministration in humans. Alcohol Clin Exp Res. 2008;32:1321-8.

55. Saunders JB, Aasland OG, Babor TF, de la Fuente JR, Grant M. Development of the alcohol use disorders identification test (AUDIT): WHO collaborative project on early detection of persons with harmful alcohol consumption-Il. Addiction. 1993;88:791-804.

56. Skinner HA, Allen BA. Alcohol dependence syndrome: measurement and validation. J Abnorm Psychol. 1982;91:199-209.

57. Flannery BA, Volpicelli JR, Pettinati HM. Psychometric properties of the penn alcohol craving scale. Alcohol Clin Exp Res. 1999;23:1289-95.

58. Murphy JG, MacKillop J. Relative reinforcing efficacy of alcohol among college student drinkers. Exp Clin Psychopharmacol. 2006;14:219-27.

59. Kiselica AM, Webber TA, Bornovalova MA. Validity of the alcohol purchase task: a meta-analysis. Addiction. 2016;111:806-16.

60. Kaplan BA, Foster RNS, Reed DD, Amlung M, Murphy JG, MacKillop J. Understanding alcohol motivation using the alcohol purchase task: A methodological systematic review. Drug Alcohol Depend. 2018;191:117-40.

61. Koffarnus MN, Franck CT, Stein JS, Bickel WK. A modified exponential behavioral economic demand model to better describe consumption data. Exp Clin Psychopharmacol. 2015;23:504-12.

62. Kaplan BA, Gilroy SP, Reed DD, Koffarnus MN, Hursh SR. The R package beezdemand: Behavioral Economic Easy Demand. Perspect. Behav Sci. 2019;42:163-80.

63. Stein JS, Koffarnus MN, Snider SE, Quisenberry AJ, Bickel WK. Identification and management of nonsystematic purchase task data: Toward best practice. Exp Clin Psychopharmacol. 2015;23:377-86.

64. Hahs-Vaughn DL Applied multivariate statistical concepts. Taylor \& Francis; 2016.

65. Narendran R, Mason NS, Paris J, Himes ML, Douaihy AB, Frankle WG. Decreased prefrontal cortical dopamine transmission in alcoholism. Am J Psychiatry. 2014;171:881-8.

66. Rominger A, Cumming $P$, Xiong $G$, Koller $G$, Boning $G$, Wulff $M$, et al. [18F] Fallypride PET measurement of striatal and extrastriatal dopamine $D$ 2/3 receptor availability in recently abstinent alcoholics. Addict Biol. 2012;17:490-503.

67. Volkow ND, Wang GJ, Maynard L, Fowler JS, Jayne B, Telang F. Effects of alcohol detoxification on dopamine D2 receptors in alcoholics: a preliminary study. Psychiatry Res. 2002;116:163-72.

68. Martinez D, Gil R, Slifstein M, Hwang DR, Huang $Y$, Perez A, et al. Alcohol dependence is associated with blunted dopamine transmission in the ventral striatum. Biol Psychiatry. 2005;58:779-86.

69. Heinz A, Siessmeier T, Wrase J, Buchholz HG, Grunder G, Kumakura Y, et al. Correlation of alcohol craving with striatal dopamine synthesis capacity and D2/3 receptor availability: a combined [18F]DOPA and [18F]DMFP PET study in detoxified alcoholic patients. Am J Psychiatry. 2005;162:1515-20.

70. Volkow ND, Wang GJ, Telang F, Fowler JS, Logan J, Jayne M, et al. Profound decreases in dopamine release in striatum in detoxified alcoholics: possible orbitofrontal involvement. J Neurosci. 2007:27:12700-6.

71. Vaughan $\mathrm{CL}$, Stangl BL, Schwandt ML, Corey KM, Hendershot CS, Ramchandani VA. The relationship between impaired control, impulsivity, and alcohol selfadministration in nondependent drinkers. Exp Clin Psychopharmacol. 2019;27:236-46. 
72. Wardell JD, Quilty LC, Hendershot CS. Impulsivity, working memory, and impaired control over alcohol: A latent variable analysis. Psychol Addict Behav. 2016;30:544-54.

73. Fritz M, Klawonn AM, Zahr NM. Neuroimaging in alcohol use disorder: From mouse to man. J Neuro Res. 2019;00:1-19. https://doi.org/10.1002/jnr.24423.

\section{ACKNOWLEDGEMENTS}

This study was funded in part by the National Institute on Alcohol Abuse and Alcoholism (NIAAA; Grant: 1R21AA023967-01A1). Dr. Le Foll has obtained funding from Pfizer (GRAND Awards, including salary support) for investigator-initiated projects. Dr. Le Foll has some in-kind donation of cannabis product from Aurora and medication donation from Pfizer and Bioprojet and was provided a coil for a TMS study from Brainsway. Dr. Le Foll has obtained industry funding from Canopy (through research grants handled by CAMH or University of Toronto), Bioprojet, ACS and Alkermes. Dr. Le Foll has received in kind donations of nabiximols from GW Pharma for past studies funded by $\mathrm{CIHR}$ and $\mathrm{NIH}$. He has been consultant for Shionogi. He is supported by $\mathrm{CAMH}$ and a clinician-scientist award from the department of Family and Community Medicine of the University of Toronto. We thank Drs. Vijay Ramchandani, Sean O'Connor, and Martin Plawecki for providing technical assistance with support from NIH P60 AA007611 (Indiana Alcohol Research Centre, Indiana University).

\section{AUTHOR CONTRIBUTIONS}

CCC contributed to the subject recruitment, study procedure execution, data analysis, and manuscript preparation. CN, MDM, and EM provided methodological oversight, contributed to data analysis and manuscript preparation. DRK provided medical oversight. DM provided oversight on manuscript preparation. IB, $\mathrm{CH}$, and BLF secured funding, and provided study design and manuscript preparation oversight.

\section{COMPETING INTERESTS}

The authors declare no competing interests.

\section{ADDITIONAL INFORMATION}

Supplementary information The online version contains supplementary material available at https://doi.org/10.1038/s41386-021-01095-2.

Correspondence and requests for materials should be addressed to C.C.C.

Reprints and permission information is available at http://www.nature.com/reprints

Publisher's note Springer Nature remains neutral with regard to jurisdictional claims in published maps and institutional affiliations. 